\title{
Comparison of Binding Parameter Constants between Sevelamer Carbonate Tablets and Renvela Tablets by a Validated Ion Chromatography Method
}

\author{
Venkata Vivekanand Vallapragada ${ }^{1,2^{*}}$, Gopichand Inti ${ }^{1}$, Sreenivas Reddy Geevanagari ${ }^{1}$, \\ Sudhakar Rao Vidiyala ${ }^{1}$, Sreeramulu Jadi $^{2}$ \\ ${ }^{1}$ Invagen Pharmaceutical Inc., Hauppauge, USA \\ ${ }^{2}$ Department of Chemistry, Sri Krishna Devaraya University, Anantapur, India \\ Email: *vvviveka@yahoo.com
}

Received March 5, 2013; revised April 15, 2013; accepted May 1, 2013

Copyright (C) 2013 Venkata Vivekanand Vallapragada et al. This is an open access article distributed under the Creative Commons Attribution License, which permits unrestricted use, distribution, and reproduction in any medium, provided the original work is properly cited.

\begin{abstract}
Sevelamer Carbonate is a crossolinked polymeric amine, it is the active ingredient in Renvela Tablets. Sevelamer Carbonate is indicated for the control of hyperphosphatamiea in patients with end-stage renal disease. The binding parameter constants of Sevelamer Carbonate were determined using the Langmuir approximation for the dosage form at $\mathrm{pH} 4.0$ and 7.0 by Ion Chromatography. An Ion Chromatogrpahy method has been developed to estimate free phosphate in in-vitro phosphate binding study of Sevelamer Carbonate Tablets. The method is selective and capable of detecting phosphate in the presence of placebo matrix. The method has been validated with a lower limit of quantitation of 0.2 $\mathrm{mM}$ for Phosphate. A linear response function was established in the range of concentrations $0.2-30.0 \mathrm{mM}(\mathrm{r}>0.99)$ for Phosphate. The intra and inter day precision values for Phosphate met the acceptance as per Food and Drug Administrations guidelines. Phosphate was stable in the set of stability studies viz. bench-top and autosampler. The developed method was applied to in-vitro phosphate binding studies of Sevelamer Carbonate Tablets.
\end{abstract}

Keywords: Binding Parameter Constants; Ion Chromatography; In-Vitro Phosphate Binding Study; Langmuir Approximation

\section{Introduction}

Sevelamer Carbonate is the active ingredient in Renvela tablets. Sevelamer Carbonate, a cross-linked poly (allylamine Carbonate), is a novel phosphate binder used for the reduction of serum phosphate levels in patients with end-stage renal disease (ESRD) [1-6]. The advantage of Sevelamer Carbonate for ESRD over existing therapies, such as calcium or aluminum supplementation, is that it is a non-absorbed, leading to an improved safety profile. There is evidence that treatment with Sevelamer Carbonate leads to the attenuation of the progression of coronary artery and aortic calcification as well as improved control of parathyroid hormone levels relative to calcium salts [7]. The structure of Sevelamer Carbonate is shown in Figure 1.

Aluminum is widely recognized as the cost effective phosphate-binding drug but its use is now generally re-

\footnotetext{
*Corresponding author.
}

stricted to ESRD patients who are uncontrolled on other agents, owing to concerns about its toxicity, including dialysis encephalopathy, osteomalacia and microcytic anaemia [8-12]. Calcium-based binders largely replaced aluminum in the 1980s and 1990s and have been the mainstay of treatment for many years [13]. However, large doses are needed with each meal leading to concerns about elevated calcium load, hypercalcaemia, and an increased potential for vascular calcification [14-16]. For this reason, current Kidney Disease Outcomes Quality Initiative (KDOQI) guidelines recommend restricting the total dose of elemental calcium provided by calcium binders to less than $1500 \mathrm{mg} /$ day in Stage 5 chronic kidney disease (CKD) patients [17].

The introduction of Sevelamer Carbonate a cationic hydrogel of cross-linked poly (allylamine Carbonate) that does not contain aluminum or calcium (third-generation binder) was a significant advance, enabling reduction of serum phosphate without adding to the patient's calcium 
load [18].

Sevelamer Carbonate (Renvela; Genzyme Corporation, Cambridge, MA) has been developed as an improved, buffered form of Sevelamer Hydrochloride (Renagel). Sevelamer Carbonate is an anion exchange resin with the same active moiety as Sevelamer Hydrochloride in which carbonate replaces chloride as the anion. The replacement of the chloride with carbonate provides bicarbonate ions that may be a benefit to patients who have CKD and are not receiving dialysis, who are prone to acidosis and do not receive the benefits of renal replacement therapy. Sevelamer Carbonate has been found to have the same safety and efficacy profile as Sevelamer Hydrochloride in hemodialysis patients [19-21].

We never come across of any publication on comparison of the binding parameter constants between Sevelamer Carbonate tablets and Renvela tablets utilizing the Langmuir approximation at various $\mathrm{pH}$ by ion chromatography. An important aspect of the analytical characterization of Sevelamer Carbonate tablets is to demonstrate equivalency to the tablet dosage form. The amines in Sevelamer Carbonate may bind phosphate ionically and through hydrogen bonding.

This paper describes the methodology and procedures for the determination the binding constants at two different $\mathrm{pH}$ levels utilizing the Langmuir approximation. A comparison of these binding constants demonstrates the equivalency of tablet dosage form at each $\mathrm{pH}$ studied. The binding study has been done on Brand tablets (Renvela Tablets $800 \mathrm{mg}$ ) as well as Sevelamer Carbonate Tablets $800 \mathrm{mg}$ produced at Invagen Pharmaceutical Inc. The binding study has been performed using the phos-

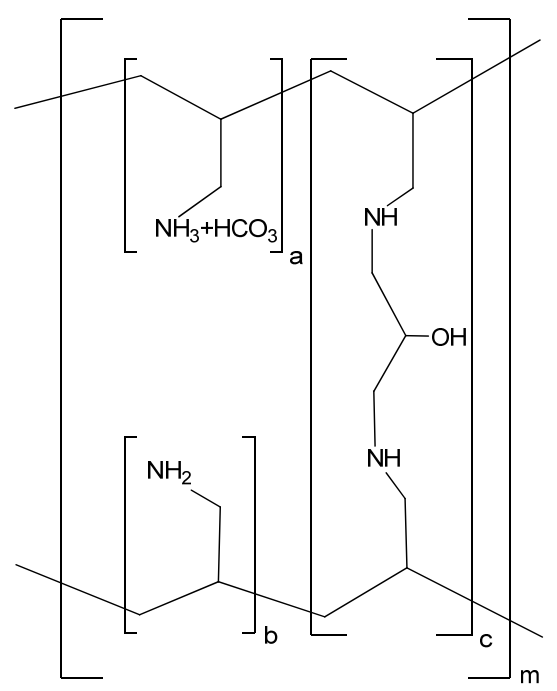

Figure 1. Chemical Structure of Sevelamer Carbonate; a, b $=$ number of primary amine groups $\mathbf{a}+\mathbf{b}=9$; $\mathbf{c}=$ number of crosslinking groups $c=1 ; n=$ fraction of protonated amines $n=0.4 ; m=$ large number to indicate extended polymer network. phate $\left(\mathrm{KH}_{2} \mathrm{PO}_{4}\right)$ buffer solutions of $1 \mathrm{mM}, 2.5 \mathrm{mM}, 5.0$ $\mathrm{mM}, 7.5 \mathrm{mM}, 10.0 \mathrm{mM}, 14.5 \mathrm{mM}, 30.0 \mathrm{mM}$ and 38.7 $\mathrm{mM}$ at two different buffers $\mathrm{pH} 4.0$ and 7.0. The method used for this study has been validated in terms of Precision, Linearity, accuracy, Limit of Quantitation and Robustness. The complete validation data demonstrate the intended purpose of the method in estimating the binding parameter constants of the Sevelamer Carbonate tablets.

\section{Materials and Methods}

\subsection{Chemicals}

Sevelamer Carbonate was obtained from Shasun Pharmaceuticals Ltd. (Chennai, India), N,N-Bis(hydroxyethyl)2-aminoethanesulfonic acid (BES) was obtained from Sigma Chemical Company (USA), Potassium phosphate monobasic $\left(\mathrm{KH}_{2} \mathrm{PO}_{4}\right)$ and $1 \mathrm{~N}$ aqueous sodium hydroxide were obtained from Spectrum Chemicals (USA). Sodium hydroxide pellets were from Spectrum Chemicals (USA). Deionised water was obtained from an in-house TOC water system (Sievers, USA). Renvela tablets purchased commercially which is manufactured by Genzyme pharmaceuticals Inc (USA). Sevelamer Carbonate Tablets 800 mg from Invagen Pharmaceutical Inc.

\subsection{Apparatus}

A Dionex (Dionex Corporation, Sunnyvale, CA) ICS5000 DC system was used for phosphate analysis. The system consists of an AS-DV Auto Sampler, ICS-5000 SP single Pump with Conductivity Detector and Chromeleon software control and data acquisition Version 7.1.1.1127. Separations were performed using a Dionex Ion Pac AS11-HC analytical column $(4 \times 250 \mathrm{~mm})$ and a Dionex ion pack AG11-HC $(4 \times 50 \mathrm{~mm})$ guard column. Suppression was achieved with an ASRS-300, $4 \mathrm{~mm}$ anion self-regenerating suppressor from Dionex. Samples were prepared in an incubated orbital shaker Max Q 4000 from Thermo Scientific.

\subsection{Chromatographic Conditions}

The mobile phase was $50 \mathrm{mM} \mathrm{NaOH}$ pumped at 0.8 $\mathrm{ml} / \mathrm{min}$. Suppression was performed in the recycle mode, with an applied current $99 \mathrm{~mA}$. Injection loop volume was $25 \mu \mathrm{L}$ with full injection setting.

\subsection{Method Development}

The major aim is to develop a suitable method with a shorter run time and more specific especially for in-vitro phosphate binding studies. The in-vitro phosphate binding study contains big analytical batch runs which need to be shorter runtimes. The buffer utilized for the binding study contains Potassium Phosphate monobasic, BES and 
$\mathrm{NaCl}$. BES and $\mathrm{NaCl}$ could contribute significant interference with phosphate peak.

IonPac AS $15(250 \times 4 \mathrm{~mm})$ column with guard column of AG15 $(50 \times 4 \mathrm{~mm})$ was employed using mobile phase with a concentration of $25 \mathrm{mM}$ Potassium Hydroxide. Under these conditions, Phosphate peak was eluted around 16 minutes with a broad peak shape. Increased the eluent concentration to $80 \mathrm{mM}$ to decrease the run time of phosphate peak. The rentention time of phosphate peak was found to be 5 minutes, however the peak shape was found to be asymmetric. In the next approach, Sodium Hydroxide was used as eluent in the concentration range of $25 \mathrm{mM}$ to $80 \mathrm{mM}$ using the same column and no significant improvement was observed in the phosphate peak shape. In another attempt, IonPac AS11-HC $(250 \times 4 \mathrm{~mm})$ with Guard column AG11 $(50 \times$ $4 \mathrm{~mm}$ ) was employed with $25 \mathrm{mM}$ Sodium hydroxide as eluent. Under these conditions, phosphate retention was found to be 14 minutes with symmetrical peak shape. To decrease the retention time of the phosphate peak increased the concentration of Sodium hydroxide to 50 $\mathrm{mM}$. The phosphate peak retention time dramatically decreased and observed around 7 minutes with symmetrical peak shape. $\mathrm{BES}$ and $\mathrm{NaCl}$ solutions were injected individually to check the interference with phosphate peak. None of them was interfered with phosphate peak. In these conditions, Chloride peak elutes around 5 minutes which is well separated from phosphate peak. Further increment in the concentration of Sodium hydroxide observed co-elution of chloride and phosphate peaks. The finalized conditions are validated as per Bioanlaytical method validation guidance, Food and drug administration.

\subsection{Validation of the Method}

\subsubsection{Selectivity}

Selectivity is the ability of an analytical method to differentiate and quantify the analyte in the presence of other components in the sample. Six independent blanks and six independent placebo preparations were analyzed for possible interference of matrix with the analyte (Phosphate). LOQ solution $(0.2 \mathrm{mM})$ was injected along with the blank and placebo solutions into Ion chromatography to check the interference of any other elements. Blank chromatogram shown in Figure 2.

\subsubsection{Placebo Binding Check}

Placebo solution is checked for any binding with media that affects the selectivity of method. Six independent solutions of Placebo equivalent to one dosage unit of Sevelamer Carbonate Tablet were prepared in $1.0 \mathrm{mM}$ $\mathrm{KH}_{2} \mathrm{PO}_{4}$ and $38.7 \mathrm{mM} \mathrm{KH}_{2} \mathrm{PO}_{4}$ respectively, to check the possible binding of placebo.

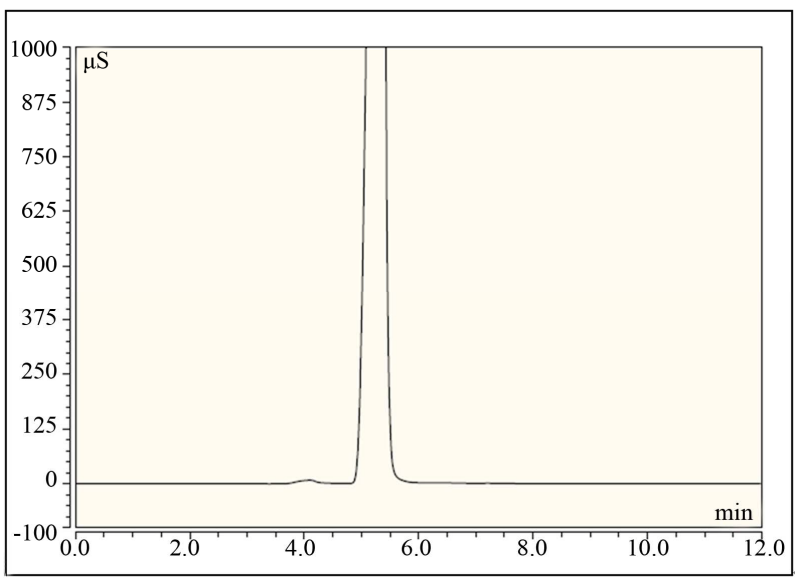

Figure 2. Typical chromatogram of Blank during selectivity study.

\subsubsection{Calibration Curve}

The calibration curve for free phosphate determination consists of a Calibration blank and six non-zero calibration standards covering concentrations ranging from 0.2 $\mathrm{mM}$ to $30.0 \mathrm{mM}$ of Monobasic Potassium Phosphate buffer $(0.2,1.0,5.0,10.0,14.5 \& 30.0 \mathrm{mM})$. Analyte corrected peak intensity values were used to set up the calibration curve and to determine QC sample concentrations. Linear Regression with linearity through zero was used to obtain the best fit of the data for the calibration curve. The acceptance criteria for each back-calculated standard concentration were $\pm 15 \%$ deviation from the nominal value except a LLOQ, which was set at $\pm 20 \%$. Calibration curve standards and quality control samples met the acceptance criteria for all experiments used in the final data, demonstrating satisfactory performance of the method during validation. The correlation coefficient for phosphate during validation study was found to be more than 0.999 which indicated good linearity. Typical calibration curve of phosphate shown in Figure 3.

\subsubsection{Precision and Accuracy}

The intra-assay precision and accuracy were estimated by analyzing replicates of Phosphate buffer solutions at four different QC levels, i.e. 0.2 (LLOQ), 0.6 (LQC), 2.0 (MQC) and 20.0 (HQC) mM. The inter assay precision was determined by analyzing the four levels QC samples on three different runs. The criteria for acceptability of the data included accuracy within $\pm 15 \%$ standard deviation (SD) from the nominal values and a precision of within $\pm 15 \%$ relative standard deviation (RSD) except for LLOQ, where it should not exceed 20\% RSD (Table 1).

\subsubsection{Stability}

The bench top stability and auto sampler stability was determined by analysing six Tablets of Sevelamer Carbonate incubated in low $(1.0 \mathrm{mM})$ and high $(38.7 \mathrm{mM})$ 


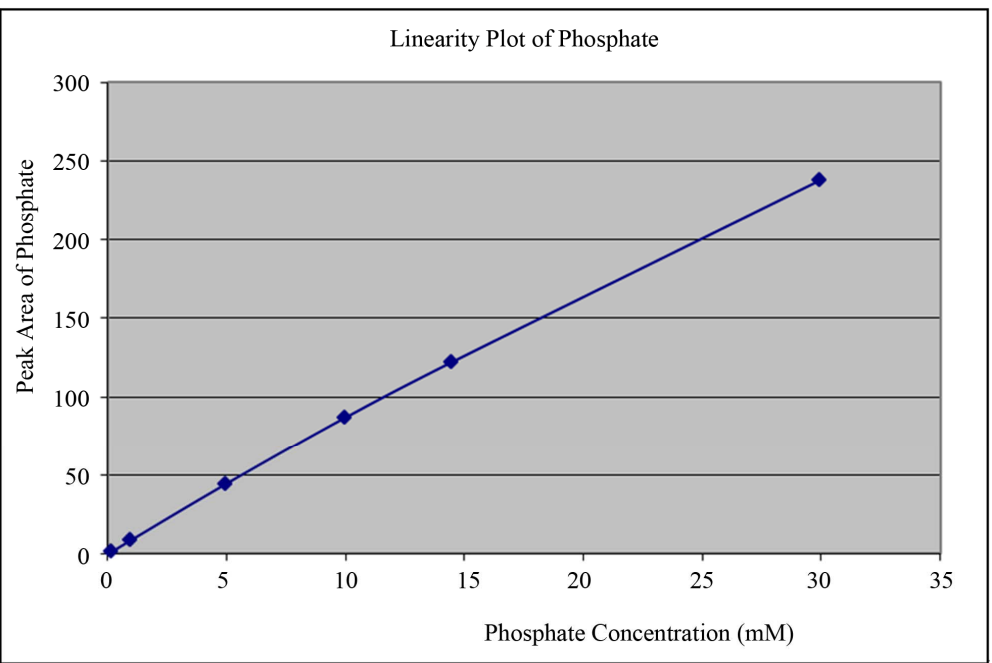

Figure 3. Calibration curve for phosphate peak generated during method validation studies.

Table 1. Intra- and inter-day precision determination quality control samples.

\begin{tabular}{|c|c|c|c|c|c|}
\hline \multicolumn{6}{|c|}{ Intra-day variation (six replicates at each concentration) } \\
\hline Theoretical concentration (mM) & Run & Average measured concentration (mM) & SD & RSD & Accuracy (\%) \\
\hline \multirow{3}{*}{0.2} & 1 & 0.198 & 0.0013 & 0.7 & 98.9 \\
\hline & 2 & 0.192 & 0.0008 & 0.4 & 96.0 \\
\hline & 3 & 0.187 & 0.0015 & 0.7 & 93.4 \\
\hline \multirow{3}{*}{0.6} & 1 & 0.601 & 0.0028 & 0.5 & 100.2 \\
\hline & 2 & 0.592 & 0.0019 & 0.3 & 98.6 \\
\hline & 3 & 0.577 & 0.0018 & 0.3 & 96.2 \\
\hline \multirow{3}{*}{2.0} & 1 & 2.033 & 0.0103 & 0.5 & 101.7 \\
\hline & 2 & 1.955 & 0.0248 & 1.6 & 99.6 \\
\hline & 3 & 1.503 & 0.0051 & 0.3 & 97.8 \\
\hline \multirow{3}{*}{20.0} & 1 & 20.700 & 0.1549 & 0.7 & 103.5 \\
\hline & 2 & 20.083 & 0.1032 & 0.5 & 100.4 \\
\hline & 3 & 19.817 & 0.1516 & 0.8 & 99.1 \\
\hline \multicolumn{6}{|c|}{ Inter-day variation (18 replicates at each concentration) } \\
\hline 0.2 & & 0.192 & 0.0055 & 2.9 & 96.2 \\
\hline 0.6 & & 0.590 & 0.0121 & 2.1 & 98.3 \\
\hline 2.0 & & 1.993 & 0.0390 & 2.0 & 99.7 \\
\hline 20.0 & & 20.200 & 0.4530 & 2.2 & 101.0 \\
\hline
\end{tabular}

concentrations of Phosphate buffer at $\mathrm{pH} 4.0$ and 7.0. As per the experimental conditions, samples were analyzed initially (0 hour), after 24 hours and 48 hours with freshly prepared calibration standards and two replicates of each low, medium and high QC's.

\subsubsection{Robustness}

Robustness is defined as degree of reproducibility of results obtained when various experimental conditions were altered such as RPM, Temperature and pH. Robustness is established by analyzing three tablets of Se- 
velamer Carbonate incubated in low (1 mM) and high (38.7 mM) concentrations of Phosphate buffers by altering the RPM (150, $200 \& 250)$, Temperature $\left(34.0^{\circ} \mathrm{C}\right.$, $37.0^{\circ} \mathrm{C}$ and $\left.40.0^{\circ} \mathrm{C}\right)$ and $\mathrm{pH}(6.80,7.00 \& 7.20,3.80,4.00$ $\& 4.20)$. The free phosphate is estimated with freshly prepared calibration standards and two sets of QC's.

\subsubsection{Phosphate Binding Plateau}

The study was performed in $38.7 \mathrm{mM}$ phosphate buffer with 6 tablets of Renvela Tablets $800 \mathrm{mg}$ in $300 \mathrm{ml}$ at $\mathrm{pH}$ 4.0 and 7.0. $10 \mathrm{ml}$ of sample was withdrawn from each vessel at time intervals of $15,30,45,60,90,120,150$ and 180 min's. The samples were filtered through 0.45 $\mu \mathrm{m}$ filters and analyzed on Ion Chromatography for binding plateau. The Phosphate binding was calculated at each interval, and found to be similar at all the time intervals (Figure 4).

\subsection{In-Vitro Phosphate Binding Study}

\section{Equilibrium Binding}

In-vitro phosphate binding study was performed on Renvela Tablets 800 mg (Genzyme) and Sevelamer Carbonate Tablets $800 \mathrm{mg}$ (Invagen). Two individual sets of aqueous phosphate solutions were prepared at the following concentration $38.7 \mathrm{mM}, 30.0 \mathrm{mM}, 14.5 \mathrm{mM}, 10.0$ $\mathrm{mM}, 7.5 \mathrm{mM}, 5.0 \mathrm{mM}, 2.5 \mathrm{mM}$ and $1.0 \mathrm{mM}$. Each set of phosphate solutions were prepared so that a final $\mathrm{pH}$ of 4.0 and 7.0 was obtained after the addition of Renvela tablets, as described below. All solutions contained 100 $\mathrm{mM}$ BES and $80 \mathrm{mM} \mathrm{NaCl}$.

The entire study has been done with Sevelamer Carbonate Tablets $800 \mathrm{mg}$ with $300 \mathrm{ml}$ volume of the phosphate buffer solution. The solutions at $\mathrm{pH} 4.0$ were prepared by adding the tablets to a set of phosphate solutions, which had no prior $\mathrm{pH}$ adjustments. Upon their disintegration, approximately $3 \mathrm{ml}$ of $1 \mathrm{~N} \mathrm{HCl}$ is added for $1.0 \mathrm{mM}$ to $14.5 \mathrm{mM}$ buffer solutions, where as $5 \mathrm{ml}$

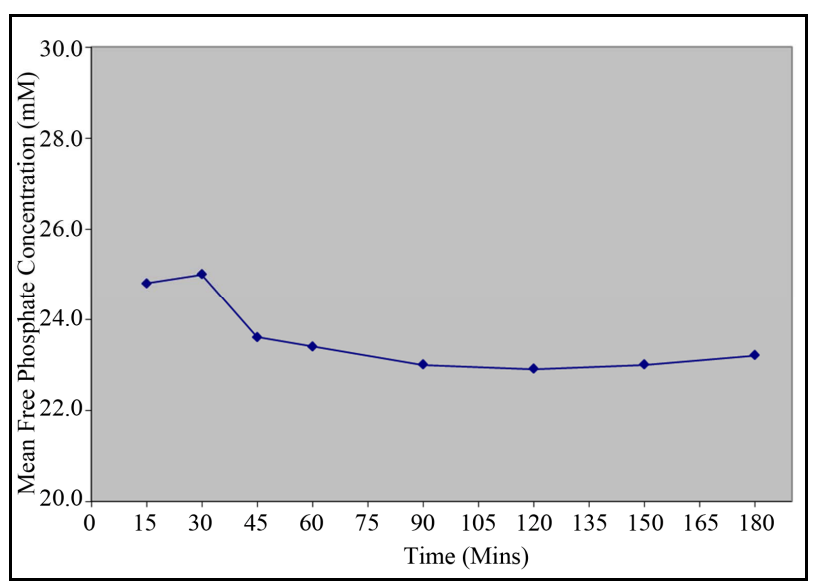

Figure 4. Phosphate Binding Plateau of Renvela Tablets 800 mg at pH 4.0. was added to $30.0 \mathrm{mM}$ and $38.7 \mathrm{mM}$ buffer solutions. The pHs of the final solutions were approximately 4.0.

The solutions at $\mathrm{pH} 7.0$ were prepared by adjusting the $\mathrm{pH}$ of each solution to 7.0 with $1 \mathrm{~N} \mathrm{NaOH}$. Approximately $50 \mathrm{ml}$ of $1 \mathrm{~N} \mathrm{NaOH}$ was volumetrically added per liter of solution. After the addition of the tablets the $\mathrm{pH}$ of the solution was approximately 7.0. Twelve tablets of Renvela and Sevelamer Carbonate were utilized at each buffer concentration. The $\mathrm{pH}$ of this solution does not change because the $\mathrm{pK}_{\mathrm{a}}$ of BES is 7.1 and thus provides excellent buffering capacity in this $\mathrm{pH}$ range. BES was utilized throughout this experiment so that a direct comparison of all results is possible. It has been demonstrated that BES, in concentrations from 60 to $120 \mathrm{mM}$, does not affect the phosphate binding.

All the samples were then placed on a Max Q 4000 incubator shaker at $37^{\circ} \mathrm{C}$ for 2 hours. The samples were removed, filtered through a $0.45 \mu \mathrm{m}$ nylon syringe filter. The samples are analyzed with the established calibration curve along with QC samples at low, medium and high concentrations were assayed in duplicate and were distributed among unknown samples in the analytical run.

A calibration curve was generated at each $\mathrm{pH}$ to produce a total of two separate 6 point calibration curves for quantitation at $\mathrm{pH} 4.0$ and 7.0. The area of the phosphate peak versus the concentration was plotted and the coefficient of determination values for each curve was greater than 0.998. Typical chromatogram of phosphate shown in Figure 5.

\subsection{Calculations}

The unbound phosphate concentrations remaining in each sample were calculated from the linear regression generated from a plot of the area of the phosphate peak versus the concentration of phosphate (mM) using the following equation:

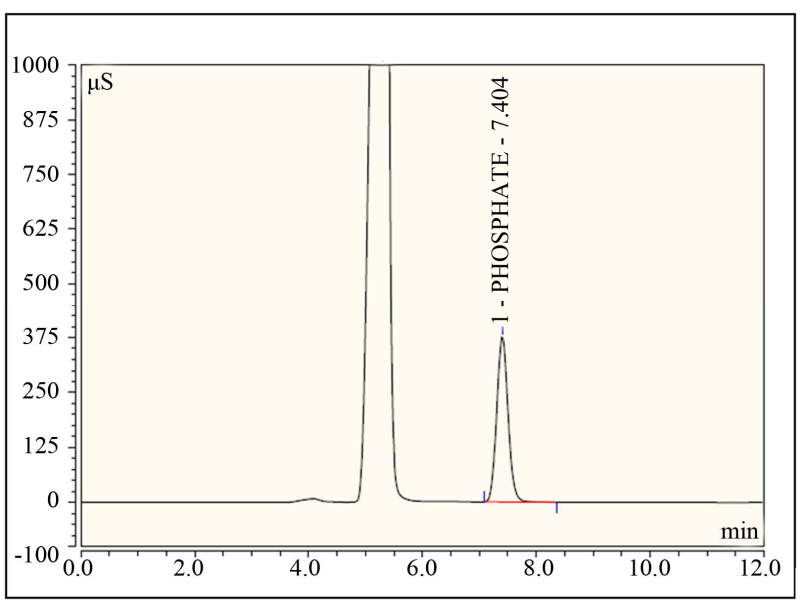

Figure 5. Typical chromatogram of Phosphate standard in calibration curve at concentration of $10 \mathrm{mM}$. 


$$
\begin{aligned}
& \text { Unbound phosphate concentration }(\mathrm{mM}) \\
& =\frac{\text { Area of phosphate }- \text { intercept }}{\text { Slope }}
\end{aligned}
$$

From the known initial concentration of phosphate in each solution before the addition of Sevelamer Carbonate (i.e. $38.7 \mathrm{mM}, 30.0 \mathrm{mM}, 14.5 \mathrm{mM}, 10.0 \mathrm{mM}, 7.5 \mathrm{mM}$, $5.0 \mathrm{mM}, 2.5 \mathrm{mM}$ and $1.0 \mathrm{mM}$ ) the bound concentration was calculated by subtracting the unbound concentration from the initial concentration.

Bound phosphate concentration $(\mathrm{mM})=$ initial concentration (mM) - Unbound phosphate concentration (mM).

The phosphate binding capacity, in mmol of phosphate/g of polymer, was calculated as follows:

$$
\begin{aligned}
& \text { Phosphate binding capacity }(\mathrm{mmol} / \mathrm{g}) \\
& =\frac{\text { bound phosphate concentration }(\mathrm{mM}) \times V_{s}}{\text { Weight }(\mathrm{g})}
\end{aligned}
$$

where $V_{s}$ is the volume of solution, approximately $0.3 \mathrm{~L}$, The weight (g) is the weight of Sevelamer Carbonate.

The phosphate binding constants were calculated from the Langmuir approximation. The monomolecular adsorption of an adsorbate (phosphate) from solution, at constant temperature, onto an adsorbent (Sevelamer Carbonate). This process is described by the Langmuir equation:

$$
\frac{C_{e q}}{x / m}=\frac{1}{k_{1} k_{2}}+\frac{C_{e q}}{k_{2}}
$$

where $C_{e q}$ is the concentration, in $\mathrm{mM}$ of phosphate remaining in solution at equilibrium or the unbound concentration. $x / m$ is the amount of phosphate bound per weight of polymer in mmol/g. The constant $k_{1}$ is the affinity constant and is related to the magnitude of the forces, which are involved in binding. The constant $k_{2}$ is the Langmuir capacity constant and is the maximum amount of phosphate that can be bound per unit weight of Sevelamer Carbonate.

The affinity and Langmuir capacity constants were calculated by performing linear regression on a plot of the unbound $(\mathrm{mM}) /$ bound $(\mathrm{mmol} / \mathrm{g})$ versus the unbound (mM) concentrations. The $k_{1}$ value is calculated by dividing the slope of the regression line by the intercept, the $k_{2}$ value is equal to the inverse of the slope (Figures 6 and 7, Table 2).

\section{Results \& Discussion}

The results demonstrate that at each $\mathrm{pH}$, no significant change observed in the Langmuir capacity constant $\left(k_{2}\right)$ and affinity constant $\left(k_{1}\right)$ was observed in Sevelamer Carbonate Tablets $800 \mathrm{mg}$ when compared with the Brand product (Renvela Tablets $800 \mathrm{mg}$ ). Sevelamer Carbonate is the phosphate bound by ion exchange of chloride and by phosphate from a solid polymer (Equation (1)). Therefore, the absolute binding capacity is difficult to predict because it depends on the degree of ion exchange varies in the presence of the placebo matrix.

\section{Conclusions}

A validated Ion Chromatography method has been developed to estimate binding parameter constants in Sevelamer Carbonate tablets. The method is selective and is capable, to detect unbound phosphate quantitatively in the binding study. The method has been validated in terms of selectivity, precision, linearity, accuracy, limit of quantification and robustness. The validated method can be used to estimate phosphate in in-vitro studies of Sevelamer Carbonate Tablets. The determinations of

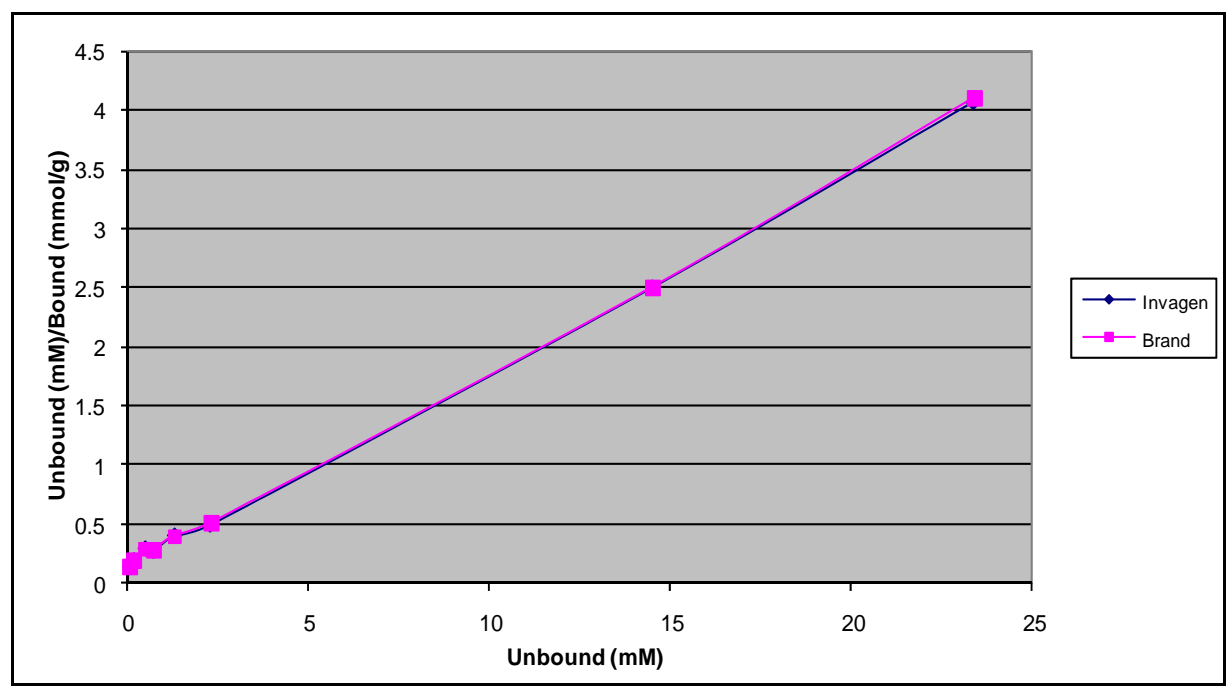

Figure 6. Langmuir plot of Sevelamer Carbonate Tablets 800 mg (Invagen) and Renvela Tablets (Brand) $800 \mathrm{mg}$ at pH 7.0. 
Table 2. The affinity and Langmuir capacity constants calculated at two pH levels.

\begin{tabular}{|c|c|c|c|c|c|c|c|c|c|}
\hline \multirow{2}{*}{ Buffer solutions } & \multicolumn{2}{|c|}{$\begin{array}{c}\text { Sevelamer carbonate } \\
\text { tablets } 800 \mathrm{mg}\end{array}$} & \multicolumn{2}{|c|}{ Renvela tablets 800 mg } & \multicolumn{3}{|c|}{$K_{1}$ (slope/intercept) } & \multicolumn{2}{|c|}{$K_{2}$ (1/slope) } \\
\hline & Slope & Intercept & Slope & Intercept & Invagen (T) & Brand (R) & T/R Ratio & Invagen & Brand \\
\hline pH 7.0 & 0.161 & 0.125 & 0.160 & 0.129 & 1.288 & 1.240 & 103.87 & 6.211 & 6.250 \\
\hline $\mathrm{pH} 4.0$ & 0.170 & 0.089 & 0.170 & 0.091 & 1.910 & 1.868 & 102.24 & 5.882 & 5.882 \\
\hline
\end{tabular}

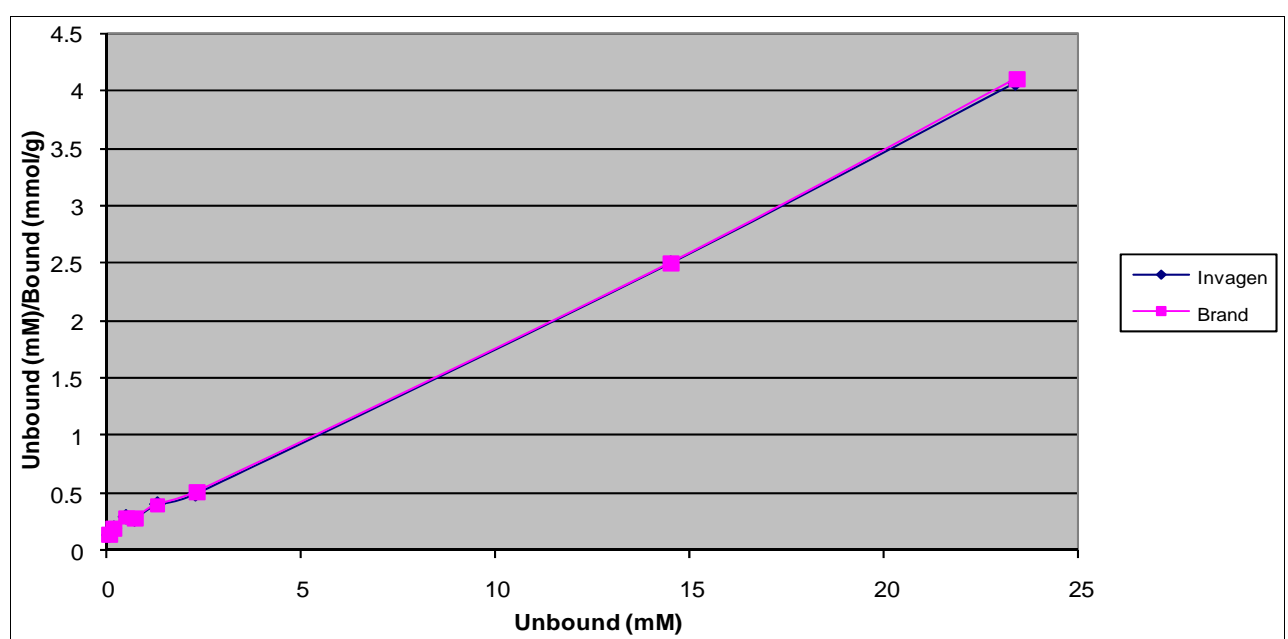

Figure 7. Langmuir plot of Sevelamer Carbonate Tablets $800 \mathrm{mg}$ (Invagen) and Renvela Tablets $800 \mathrm{mg}$ (Brand) at pH 4.0.

$$
\mathrm{R}-\mathrm{NH}_{3}+\mathrm{HCO}_{3}^{-}(s)+\mathrm{H}_{2} \mathrm{PO}_{4}^{-}(a q) \rightarrow \mathrm{R}-\mathrm{NH}_{3}+\mathrm{H}_{2} \mathrm{PO}_{4}^{-}(s)+\mathrm{HCO}_{3}^{-}(a q)
$$

binding parameter constants were compared between Renvela Tablets (Brand) and Sevelamer Carbonate Tablets (Invagen) and results are in good agreement.

\section{Acknowledgements}

The authors wish to thank the management of Invagen pharmaceutical Inc. for supporting this work. We would also like to thank colleagues in analytical development of Invagen pharmaceutical Inc. for their co-operation in carrying out this work.

\section{REFERENCES}

[1] D. P. Rosenbaum, H. S. R. Farley, W. H. Mandeville, M. Pitruzzello and D. I. Goldberg, "Effect of RenaGel, a Non-Abosrbable, Cross-Linked, Polymeric Phosphate Binder, on Urinary Phosphorus Excretion in Rats," Nephrology Dialysis Transplantation, Vol. 12, No. 5, 1997, pp. 961-964. doi:10.1093/ndt/12.5.961

[2] G. M. Chertow, S. K. Burke, J. M. Lazarus, K. H. Stenzel, D. Wombolt, D. Goldberg, et al., "Poly Allylamine Chloride (RenaGel): A Noncalcemic Phosphate Binder for the Treatment of Hyperphosphatemia in Chronic Renal Failure,” American Journal of Kidney Diseases, Vol. 29, No. 1, 1997, pp. 66-71. doi:10.1016/S0272-6386(97)90009-3

[3] S. K. Burke, E. A. Slatopolsky and D. Goldberg, "RenaGel, a Novel Calcium- and Aluminium-Free Phosphate
Binder, Inhibits Phosphate Absorption in Normal Volunteers,” Nephrology Dialysis Transplantation, Vol. 12, No. 8, 1997, pp. 1640-1644. doi:10.1093/ndt/12.8.1640

[4] R. A. Swearingen, X. Chen, J. S. Petersen, K. S. Riley, D. Wang and E. Zhorov, "Determination of the Binding Parameter Constants of Renagel Capsules and Tablets Utilizing the Langmuir Approximation at Various $\mathrm{pH}$ by Ion Chromatography," Journal of Pharmaceutical and Biomedical Analysis, Vol. 29, No. 1-2, 2002, pp. 195-201. doi:10.1016/S0731-7085(02)00007-9

[5] J. R. Mazzeo, R. M. Peters, M. R. Hanus, X. Chen and K. A. Norton, "A Phosphate Binding Assay for Sevelamer Hydrochloride by Ion Chromatography,” Journal of Pharmaceutical and Biomedical Analysis, Vol. 19, No. 6, 1999, pp. 911-915. doi:10.1016/S0731-7085(98)00193-9

[6] S. R. H. Farley, W. H. Manderville, J. Ward and K. L. Miller, "Design and Characterization of Sevelamer Hydrochloride: A Novel Phosphate-Binding Pharmaceutical,” Journal of Macromolecular Science, Part A: Pure and Applied Chemistry, Vol. 36, No. 7-8, 1999, pp. 10851091.

[7] G. M. Chertow, S. K. Burke and P. Raggi, "Sevelamer Attenuates the Progression of Coronary and Aortic Calcification in Hemodialysis Patients," Kidney International, Vol. 62, No. 1, 2002, pp. 245-252. doi:10.1046/j.1523-1755.2002.00434.X

[8] A. C. Alfrey, G. R. LeGendre and W. D. Kaehny, “The Dialysis Encephalopathy Syndrome, Possible Aluminum 
Intoxication," The New England Journal of Medicine, Vol. 294, No. 4, 1976, pp. 184-188. doi:10.1056/NEJM197601222940402

[9] I. S. Parkinson, M. K. Ward and D. N. S. Kerr, "Dialysis Encephalopathy, Bone Disease and Anaemia: The Aluminium Intoxication Syndrome during Regular Haemodialysis," Journal of Clinical Pathology, Vol. 34, No. 11, 1981, pp. 1285-1294. doi:10.1136/jcp.34.11.1285

[10] J. J. Plachot, G. C. Witmer, S. Halpern, V. Mendes, A. Bourdeau, J. Fritsch, et al., "Bone Ultrastructure and XRay Microanalysis of Aluminum-Intoxicated Hemodialyzed Patients,” Kidney International, Vol. 25, No. 5, 1984, pp. 796-803. doi:10.1038/ki.1984.92

[11] H. H. Malluche and M. M. Faugere, "Risk of Adynamic Bone Disease in Dialyzed Patients,” Kidney International Supplement, Vol. 38, No. 38, 1992, pp. S62-S67.

[12] M. Touam, F. Martinez, B. Lacour, R. Bourdon, J. Zingraff, S. Di Giulio, et al., "Aluminium-Induced, Reversible Microcytic Anemia in Chronic Renal Failure: Clinical and Experimental Studies," Clinical Nephrology, Vol. 19, No. 6, 1983, pp. 295-298.

[13] M. Wallot, K. E. Bonzel, A. Winter, B. Georger, B. Lettgen and M. Bald, "Calcium Acetate versus Calcium Carbonate as Oral Phosphate Binder in Pediatric and Adolescent Hemodialysis Patients," Pediatric Nephrology, Vol. 10, No. 5, 1996, pp. 625-630. doi:10.1007/s004670050175

[14] W. G. Goodman, J. Goldin, B. D. Kuizon, C. Yoon, B. Gales, D. Sider, et al., "Coronary-Artery Calcification in Young Adults with End-Stage Renal Disease Who Are Undergoing Dialysis," The New England Journal of Medicine, Vol. 342, No. 20, 2000, pp. 1478-1483. doi:10.1056/NEJM200005183422003

[15] J. A. Delmez, C. A. Tindira, D. W. Windus, K. Y. Norwood, K. S. Giles, T. L. Nighswander, et al., "Calcium
Acetate as a Phosphorus Binder in Hemodialysis Patients," Journal of the American Society of Nephrology, Vol. 3, No. 1, 1992, pp. 96-102.

[16] C. H. Hsu, "Are We Mismanaging Calcium and Phosphate Metabolism in Renal Failure?” American Journal of Kidney Diseases, Vol. 29, No. 4, 1997, pp. 641-649. doi:10.1016/S0272-6386(97)90352-8

[17] G. Eknoyan, A. Levin and N. W. Levin, "Bone Metabolism and Disease in Chronic Kidney Diseases,” American Journal of Kidney Diseases, Vol. 42, Suppl. 3, 2003, pp. 1-201. doi:10.1016/S0272-6386(03)00905-3

[18] W. Y. Qunibi, R. E. Hootkins, L. L. McDowell, M. S. Meyer, M. Simon, R. O. Garza, et al., "Treatment of Hyperphosphatemia in Hemodialysis Patients: The Calcium Acetate Renagel Evaluation (CARE Study)," Kidney International, Vol. 65, No. 5, 2004, pp. 1914-1926. doi:10.1111/j.1523-1755.2004.00590.x

[19] D. J. Block, J. Robertson, T. S. Chasan, A. Blair, M. Dillon and A. J. Bleyer, "A Randomized, Double-Blind, Cross-Over Design Study of Sevelamer Hydrochloride and Sevelamer Carbonate in Patients on Hemodialysis," Clinical Nephrology, Vol. 68, 2007, pp. 386-391.

[20] M. Hanus, E. Zhorov, D. Brommage, M. Plone and H. S. R. Farley, "Assessment of Phosphate Binding by Sevelamer Carbonate Powder for Oral Suspension Mixed in Foods," Nephrology Nursing Journal, Vol. 39, No. 9, 2012, pp. 239-243,255.

[21] M. Ketteler, M. Rix, S. Fan, N. Pritchard, O. Oestergaard, S. C. Taber, et al., "Efficacy and Tolerability of Sevelamer Carbonate in Hyperphosphatemic Patients Who Have Chronic Kidney Disease and Are Not on Dialysis," Clinical Journal of the American Society of Nephrology, Vol. 3, No. 4, 2008, pp. 1125-1130. doi:10.2215/CJN.05161107 